\title{
LA FINANCIACIÓN PÚBLICA DE LAS CONFESIONES RELIGIOSAS Y EL PRINCIPIO DE IGUALDAD. A PROPÓSITO DE LA STS DE 14 DE DICIEMBRE DE 2016
}

\author{
JOSÉ RAMÓN POLO SABAU ${ }^{1}$ \\ Universidad de Málaga \\ ipolo@uma.es
}

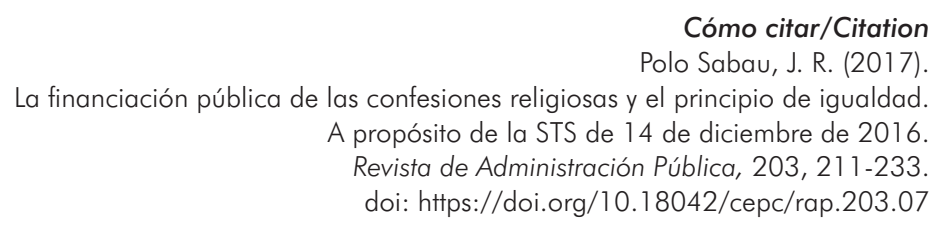

\section{Resumen}

En este trabajo se estudia el contenido de la Sentencia del Tribunal Supremo de 14 de diciembre de 2016, en la que se desestimó un recurso de casación interpuesto por la Federación de Entidades Religiosas Evangélicas de España contra la sentencia de la Audiencia Nacional que avaló la actuación administrativa que, previamente, había rechazado la pretensión de dicha entidad, encauzada por la vía del derecho de petición, de acceder al sistema de financiación mediante la llamada asignación tributaria en condiciones similares a las que ya rigen para la Iglesia católica.

\section{Palabras clave}

Derecho eclesiástico del Estado; financiación de las confesiones religiosas; igualdad religiosa; relaciones Iglesia-Estado.

\footnotetext{
1 Catedrático de Derecho Eclesiástico del Estado.
} 


\section{Abstract}

This paper deals with the study of the Spanish Supreme Court's judgement of December 14, 2016, deciding a case involving the attempt by of the Spanish Federation of Evangelical Organizations to gain access to the same public funding procedure via the tax system that currently is available in Spain only for the Catholic Church.

\section{Keywords}

Religious organizations public funding; religious non-discrimination; Church and State; Law and Religion. 


\section{SUMARIO}

I. INTRODUCCIÓN. II. LOS HECHOS DEL CASO. III. LA FUNDAMENTACIÓN JURÍDICA DEL FALLO: EL ALCANCE DEL DERECHO DE PETICIÓN. IV. REFERENCIAS INCIDENTALES EN LA SENTENCIA AL PRINCIPIO DE IGUALDAD RELIGIOSA. V. UNA BREVE REFLEXIÓN FINAL.

\section{INTRODUCCIÓN}

Como es notorio, la financiación estatal de la Iglesia católica mediante el mecanismo de la llamada asignación tributaria tiene un carácter excepcional en nuestro derecho, como asimismo lo tienen otras vías de financiación pública de esta confesión tales como la subvención directa de una serie de concretas áreas de actividad - $v$. $g r$. la enseñanza o la asistencia religiosas en determinados centros públicos ${ }^{2}$.

Así, en efecto, exceptuando la intervención estatal orientada a sufragar el coste de la enseñanza religiosa en las escuelas públicas también de las comúnmente denominadas confesiones minoritarias - las que suscribieron con el Estado los acuerdos de $1992^{3}$ —, que por lo demás se desarrolla bajo unas

2 La bibliografía relativa a la financiación de las confesiones religiosas en general y de la Iglesia católica en particular es muy extensa y, dadas las características de este comentario jurisprudencial, no parece adecuado hacer aquí sino una breve mención al hecho de que podrá encontrarse una exposición general de este asunto en cualquiera de los tratados y manuales universitarios de la asignatura de Derecho Eclesiástico del Estado (o de la más reciente asignatura de Derecho y Factor religioso, presente en el Grado en Derecho en muchas de nuestras universidades desde la implantación del EEES).

3 Se trata de los acuerdos de cooperación con la Federación de Entidades Religiosas Evangélicas de España, con la Federación de Comunidades Israelitas de España y con la Comisión Islámica de España, aprobados, respectivamente, por las leyes 24, 25 y 26/1992, de 10 de noviembre. La disposición final sexta de la Ley 15/2015, de 2 de julio, de la jurisdicción voluntaria ha modificado la denominación de la segunda de 
condiciones más restrictivas y en unos términos bien distintos a los que caracterizan a la enseñanza de la religión católica en esos mismos centros educativos de titularidad estatal, lo cierto es que nuestro ordenamiento jurídico no contempla otros cauces de financiación pública directa de las confesiones distintas de la católica, disfrutando las precitadas confesiones minoritarias con acuerdo de cooperación únicamente de una serie de exenciones y beneficios fiscales específicos además de los generalmente previstos para las entidades sin ánimo de lucro ${ }^{4} \mathrm{y}$, asimismo, de los muy limitados recursos provenientes de la Fundación Pluralismo y Convivencia que, además, en ningún caso podrán destinarse a costear actividades de naturaleza netamente religiosa, tal y como se desprende de la normativa por la que se rige esta entidad del sector público estatal.

La Fundación Pluralismo y Convivencia fue creada por acuerdo del Consejo de Ministros de 15 de octubre de 2004 y, en efecto, en el art. 7.1 de sus actuales estatutos se dispone que «la Fundación tiene por objeto contribuir a la ejecución de programas y proyectos de carácter cultural, educativo y de integración social de las confesiones no católicas con Acuerdo de cooperación con el Estado español o con "notorio arraigo" en España» (las cursivas son mías); de ello cabe inferir que los fondos provenientes de esta institución no podrán destinarse a financiar actividades de índole estrictamente religiosa, y así de hecho lo aclara la Memoria de actividades de la Fundación correspondiente al ańo 2005, en la que puede leerse que «parece lógico que el Estado español en tanto que laico, con una laicidad positiva, no contribuya a financiar el culto, pero nada impide su apoyo a actividades de interés general que sean desarrolladas por las confesiones minoritarias» (las cursivas vuelven a ser mías). Al hilo de este asunto dejo aquí ahora solo apuntada esta enorme paradoja que, sin necesidad de hacer un gran esfuerzo de interpretación, se deriva claramente de todo ello: por un lado, es la propia Administración — no olvidemos que se trata de una Fundación del sector público estatal — la que está calificando de ilógica en un Estado laico como el nuestro la financiación directa del culto religioso y la que, por tanto, está aparentemente apoyándose, en su configuración normativa, en el criterio tempranamente avanzado por el Tribunal Constitucional en cuya virtud el principio de aconfesionalidad impide concurrir al Estado en sociedad en calidad de sujeto de actos o actitudes de signo religioso y, asimismo, prohíbe confundir las funciones civiles y las religiosas (STC 24/1982); por otro, es ese mismo Estado el que, sin embargo,

estas entidades - y por consiguiente también la del acuerdo correspondiente- que ha pasado ahora a llamarse Federación de Comunidades Judías de España.

4 Este conjunto de exenciones y beneficios fiscales se encuentra originariamente recogido en el respectivo art. 11 de cada uno de los acuerdos de cooperación de 1992. 
no tiene inconveniente alguno en financiar directamente actividades netamente religiosas (sostenimiento del clero, asistencia religiosa en instituciones públicas, etc.) cuando se trata de la Iglesia católica sin que en apariencia esto haya suscitado similares recelos ni le haya parecido ello en absoluto ilógico a la Administración a la luz del principio de laicidad o aconfesionalidad. La diferencia de criterio es más que evidente aunque, como decía, este de la implicación en este asunto del principio de aconfesionalidad es un tema que, en tanto que abordado aquí solo incidentalmente, debe quedar en este momento solo esbozado, pues sin duda merece un análisis más extenso e incisivo del que pretendo realizar en estas páginas, centradas más bien en las implicaciones que también tiene en esta cuestión el principio de igualdad ${ }^{5}$.

Así pues, y volviendo al tema que constituye el principal objeto de este comentario, hay que hacer notar que recientemente el Tribunal Supremo ha dictado su Sentencia de 14 de diciembre de 2016, en la que se desestima el recurso de casación interpuesto por la Federación de Entidades Religiosas Evangélicas de España (FEREDE) contra la Sentencia dictada el 25 de mayo de 2015 por la Sección Séptima de la Sala de lo Contencioso-Administrativo de la Audiencia Nacional, sentencia esta última que, a su vez, había resuelto, asimismo desestimándolo, un recurso interpuesto contra la resolución del Ministerio de Hacienda y Administraciones Públicas de 26 de enero de 2015 que, en su momento, rechazó la pretensión de dicha Federación de beneficiarse también del sistema de la asignación tributaria mediante la instauración de una casilla similar en el IRPF a aquella de la que ya dispone la Iglesia católica, alegando la entidad recurrente, entre otros aspectos, la vulneración del principio constitucional de igualdad.

La mencionada aspiración de la FEREDE fue inicialmente encauzada por la vía del derecho de petición, lo que de entrada se antoja muy problemático si es que no directamente inadecuado, y, de hecho, como se verá, así se lo pareció a la postre a nuestro máximo órgano jurisdiccional, pues, conviene dejarlo ya sentado, en la precitada Sentencia de 14 de diciembre de 2016 el grueso de la argumentación con la que el Tribunal Supremo fundamenta su fallo desestimatorio gira precisamente en torno a la ausencia en este caso de vulneración de aquel derecho fundamental reconocido en el art. 29 de la Constitución. Esta circunstancia hace que el Tribunal no vea la necesidad de pronunciarse sobre la presunta vulneración de otros derechos fundamentales

5 Me he ocupado con mayor detenimiento entre otros de este aspecto concreto en J. R. Polo Sabau (2014), «Reflexiones sobre el fundamento constitucional de la financiación pública de las confesiones religiosas», Revista General de Derecho Constitucional, 18, pág. 3. También publicado en J. R. Polo Sabau (2014), Dimensiones de la libertad religiosa en el Derecho español, Barcelona: J. M. Bosch. 
que, según el recurrente, había asimismo tenido lugar al no haberse atendido adecuadamente a su petición, ya que, en esencia ahora, lo que la sentencia concluye es que el derecho de petición sí fue aquí respetado conforme a las exigencias que su ley reguladora establece en relación con su ejercicio, al margen de que eventualmente no se concediese aquello que se solicitó.

Ello no obstante, la resolución del Tribunal Supremo incidentalmente hace algunas referencias al principio de igualdad religiosa que, aunque muy breves y aparentemente sin una repercusión significativa en la fundamentación del fallo, no dejan de tener un cierto interés e invitan, cuando menos, a formular algunas reflexiones al respecto, que es precisamente lo que me dispongo a realizar en el último epígrafe de este trabajo, una vez expuesto y sintéticamente glosado el contenido de esta sentencia de 14 de diciembre de 2016.

\section{LOS HECHOS DEL CASO}

La FEREDE, ejerciendo en este caso el derecho de petición que reconoce nuestro ordenamiento, solicitó en su día al Ministerio de Hacienda y Administraciones Públicas que se le permitiese acceder al llamado sistema de la asignación tributaria y que para ello se incluyese en el IRPF una casilla que, a semejanza de la que ya existe en relación con la Iglesia católica, concediese a aquellos contribuyentes que así lo desearen la posibilidad de destinar el 0,7\% de la cuota de su impuesto a financiar a la Iglesia protestante o evangélica.

Mediante resolución de 26 de enero de 2015, la respuesta de dicho departamento ministerial ante esta solicitud fue, en lo esencial, la de que la existencia de ese modelo de financiación de la Iglesia católica a través de la asignación tributaria se basaba estrictamente en lo previsto en el correspondiente acuerdo de cooperación entre el Estado español y la Santa Sede (Acuerdo sobre asuntos económicos de 3 de enero de 1979) ${ }^{6}$ y, por tanto, a falta de una similar disposición acordada con las restantes confesiones no procedía atender a la petición en este caso de la FEREDE.

La entidad religiosa, subsiguientemente, impugnó la referida resolución administrativa denegatoria de su petición, interponiendo contra ella, ante la

6 Según dispone el art. II.2 del citado acuerdo de cooperación, «transcurridos tres ejercicios completos desde la firma de este Acuerdo, el Estado podrá asignar a la Iglesia Católica un porcentaje del rendimiento de la imposición sobre la renta o el patrimonio neto u otra de carácter personal, por el procedimiento técnicamente más adecuado. Para ello, será preciso que cada contribuyente manifieste expresamente en la declaración respectiva, su voluntad acerca del destino de la parte afectada. En ausencia de tal declaración la cantidad correspondiente se destinará a otros fines». 
Audiencia Nacional, un recurso por la vía de la protección jurisdiccional de los derechos fundamentales contemplada en los arts. 114 y sigs. de la Ley 29/1998, de 13 de julio, reguladora de la jurisdicción contencioso-administrativa. Los alegatos de la parte recurrente ante esta instancia judicial son expuestos de manera condensada en el Fundamento Jurídico Primero de la sentencia del Tribunal Supremo que es objeto de este comentario, en los términos que siguen:

[...] en su demanda FEREDE alegó que la resolución de 26 de enero de 2015 no contiene ningún argumento de hecho o de Derecho que justifique la grave limitación de los derechos fundamentales de quienes practican el culto protestante o evangélico. Y, frente a cuanto dice el Ministerio de Hacienda y Administraciones Públicas sobre el acuerdo con la Santa Sede, adujo que también FEREDE tiene suscrito un acuerdo con el Estado, aprobado por la Ley 24/1992, de 10 de noviembre, y que no deben recibir un trato distinto en lo esencial unas y otras entidades religiosas pues, de lo contrario, habrá discriminación. Al respecto, invoca los arts. 14 y 16.1 y 3 de la Constitución además de llamar la atención sobre la aconfesionalidad del Estado que proclama ese art. 16.3.

La pretensión de la FEREDE tampoco prosperó en aquella primera impugnación en el ámbito jurisdiccional, siendo dictada por la Sección Séptima de la Sala de lo Contencioso-Administrativo de la Audiencia Nacional la Sentencia de 25 de mayo de 2015 por la que se desestima en todas sus partes el recurso al considerar, se afirma en el fallo, que aquella pretensión excede de las competencias de la Administración demandada.

Nuevamente es lo reflejado en el Fundamento Jurídico Primero de la STS de 14 de diciembre de 2016 lo que me servirá ahora para exponer sintéticamente los argumentos de la Audiencia Nacional en apoyo de su desestimación, básicamente alusivos, por un lado, al alcance del derecho de petición en cuyo ejercicio se presentó inicialmente la solicitud por parte de la FEREDE ante el órgano administrativo, y, por otro, a la supuesta falta de competencia de la Administración para atender unilateralmente a una pretensión que, según se alega en la resolución de la Audiencia, requeriría por el contrario de la previa existencia de una disposición acordada por el Estado con las confesiones evangélicas:

[...] La sentencia de la Audiencia Nacional, al justificar su fallo desestimatorio, señala, en primer lugar, cuál es el contenido que al derecho de petición, reconocido por el art. 29 de la Constitución, da la Ley Orgánica 4/2001, de 12 de noviembre, que lo regula. Subraya, al respecto, que el de petición no comporta el derecho a obtener lo que se pide sino solamente a que se acuse 
recibo de la misma y se comunique al peticionario la decisión adoptada. Además, explica que el Convenio celebrado entre España y la Santa Sede el 3 de enero de 1979, en su Anexo IV, dedicado al régimen económico, art. II, recoge el compromiso del Estado de asignar a la Iglesia Católica un porcentaje del rendimiento del impuesto sobre la renta o sobre el patrimonio o sobre cualquier otro de carácter personal siempre que así lo manifieste expresamente cada contribuyente. También, da cuenta de que la Ley 24/1992 contempla el régimen fiscal de los bienes y actuaciones de FEREDE pero sin prever ninguna previsión semejante a la del Convenio con la Santa Sede. Por eso, concluye la sentencia, el establecimiento de un mecanismo como el pedido por la recurrente requerirá de un convenio entre el Estado y la instancia representativa de las confesiones religiosas que lo pretenden y que la Administración no puede establecerlo de manera unilateral.

Frente a la resolución desestimatoria de la Audiencia Nacional, la FEREDE interpuso el correspondiente recurso de casación, basándose en una serie de argumentos que se encuentran fielmente resumidos en este caso en el Fundamento Jurídico Segundo de la sentencia del Tribunal Supremo de 14 de diciembre de 2016:

El escrito de interposición del recurso de casación reprocha a la sentencia de instancia, bajo la invocación del apartado d) del art. 88.1 de la Ley de la Jurisdicción, la infracción de los arts. 14 y 16.1 y 3 de la Constitución y los argumentos con los que explica esas vulneraciones son los que, seguidamente, resumimos.

Se queja, en primer lugar, FEREDE de que la Administración, al no acceder a su petición, ha desconocido el derecho fundamental de las personas a la igualdad en la Ley que proclama el art. 14 de la Constitución pues es evidente el trato desigual que recibe en comparación con el dado a la Iglesia Católica. No le parece válida a la recurrente la razón que se le ha dado para explicar esa diferencia, es decir, la remisión a los Acuerdos con la Santa Sede porque entiende que con ella se elude el fondo del asunto. Se desconoce, en realidad, que también se puede incorporar a los acuerdos del Estado con las entidades religiosas protestantes la previsión que les permita recibir el porcentaje mencionado del impuesto pero que no se ha hecho nada «que tienda a dar neutralidad a la distribución tributaria», ni se está «dispuesto a poner fin a la histórica discriminación o trato desigual de las distintas denominaciones religiosas ante las leyes tributarias».

A continuación, denuncia la vulneración del derecho a la libertad ideológica y a la libertad religiosa reconocido en el art. 16.1 de la Constitución, porque la limitación presupuestaria comporta una limitación operativa de la actividad religiosa.

En tercer lugar, mantiene FEDERE que se ha vulnerado el derecho fundamental de las personas a la aconfesionalidad del Estado establecido en 
el art. 16.3, siempre de la Constitución. También se infringe, dice, el mandato que este precepto dirige al Estado de que tenga en cuenta las creencias de los españoles y mantenga relaciones de cooperación con todas las confesiones religiosas y no sólo con la católica.

Además, FEDERE afirma que se ha infringido el derecho reconocido por el art. 16.1 del texto fundamental a expresar y difundir libremente los pensamientos, opiniones e ideas y, por último, sostiene que se ha vulnerado el derecho fundamental de petición porque la resolución administrativa impugnada en la instancia no entró en el fondo de la cuestión.

Respecto de esto último, no considera aceptables las razones ofrecidas por la resolución de 26 de enero de 2015 porque la Iglesia Católica, además de las exenciones tributarias que también tiene la Iglesia Protestante, percibe el porcentaje conocido de la cuota del Impuesto sobre la Renta de las Personas Físicas. En realidad, ańade, la Administración se ha limitado a decir que lo pedido escapa a su competencia pero no lo ha justificado ni dirigido la petición a los organismos competentes y la sentencia, al dar por bueno el proceder de la Administración, incurre en las infracciones del ordenamiento jurídico señaladas.

Esta pretensión casacional se vio finalmente frustrada merced a lo establecido en la sentencia del Tribunal Supremo de 14 de diciembre de 2016, de la que fue ponente el magistrado don Pablo Lucas Murillo de la Cueva y que decretó no haber lugar al recurso de casación, declarando conforme a derecho la sentencia de la Audiencia Nacional que había sido objeto de impugnación.

\section{LA FUNDAMENTACIÓN JURÍDICA DEL FALLO: EL ALCANCE DEL DERECHO DE PETICIÓN}

Como se anticipó, la forma en la que fue inicialmente encauzada su pretensión por parte de la FEREDE, por la vía del ejercicio del derecho de petición, condiciona decisivamente el resultado del fallo en la medida en la que el Tribunal Supremo, al igual que hizo previamente la sentencia de instancia, considera que no se ha producido aquí la vulneración de aquel derecho fundamental, razón por la cual, con la única excepción de alguna referencia muy incidental al principio de igualdad religiosa a la que después aludiré, ni tan siquiera entra a valorar el supuesto incumplimiento de los otros preceptos constitucionales ${ }^{7}$ que la entidad recurrente decía haberse producido, derivadamente, a causa de esa presunta lesión del derecho de petición.

7 Aunque este es un aspecto que requeriría sin duda una más prolija argumentación, nótese que utilizo deliberadamente aquí esta expresión y no la del incumplimiento o la vulneración de otros derechos fundamentales, que es lo que literalmente se aduce 
Así, tras haber dilucidado una cuestión de orden procedimental relativa a ciertos supuestos defectos de forma que alegaban tanto el abogado del Estado como también el Ministerio Fiscal y que, según estos, eran por sí mismos causa suficiente para desestimar el recurso ${ }^{8}$, el Tribunal se centra en explicar las razones por las que estima que el derecho de petición ha sido aquí respetado en todos sus extremos, conforme a su estatuto constitucional y a las condiciones de ejercicio explicitadas en su ley reguladora.

Ello requiere, en primer lugar, de la determinación del alcance del derecho de petición en nuestro ordenamiento jurídico, lo que acontece resumidamente en este caso en el Fundamento Jurídico Quinto:

FEREDE presentó su solicitud en ejercicio del derecho fundamental de petición que reconoce el art. 29 de la Constitución y regula la Ley Orgánica 4/2001.

por parte del recurrente, ya que considero que no todos los preceptos invocados son en rigor declarativos de un derecho fundamental: concretamente se me antoja cuando menos muy discutible que se pueda hablar de un derecho fundamental de las personas a la aconfesionalidad del Estado, a partir de lo estipulado en el art. 16.3, aunque como digo esta es una cuestión colateral que solo pretendo ahora dejar apuntada.

En relación con los alegatos del abogado del Estado, en el Fundamento Jurídico Tercero se expone que este «dice, en primer lugar, que está condenado al fracaso [el recurso de casación] porque se limita a reiterar lo alegado en la demanda y esos argumentos ya fueron analizados por la sentencia y desestimados. $Y$ la jurisprudencia es clara sobre la improcedencia de que el escrito de interposición se limite a reproducir lo dicho en la instancia en vez de realizar una crítica de la sentencia impugnada»; similarmente, en el Fundamento Jurídico Cuarto se relata que el Ministerio Fiscal, «tras resaltar la que considera confusa formulación de los escritos de preparación y de interposición, observa que en el primero no hay ninguna referencia al derecho de petición que sí aparece en el segundo. Esos defectos formales le parecen suficientes para desestimar el recurso. Igualmente, ha de conducir al mismo resultado, dice, la constatación de que el recurrente se refiere a la actuación administrativa en vez de argumentar sobre los fundamentos de la sentencia»; todas estas argumentaciones son en efecto preliminarmente desechadas por el Tribunal, en el Fundamento Jurídico Quinto, en los siguientes términos: «es verdad que el escrito de preparación no menciona al derecho de petición expresamente y que el escrito de interposición parece referirse más a la actuación administrativa o a la posición del Estado que a la sentencia contra la que se deben dirigir los motivos de casación. No obstante, es claro que FEREDE está combatiendo el fallo de la sentencia y los argumentos en que descansa y que pretende hacer valer el derecho de petición en el particular entendimiento del mismo que defiende. Así, pues, los defectos formales no deben impedirnos entrar en el examen de los motivos de casación, los cuales, hemos de anunciarlo ya, no pueden prosperar». 
Esta figura se distingue por servir de cauce para aquellas pretensiones que no tienen estatuto de derecho ni de interés legítimo. Y se ha caracterizado, por un lado, por impedir que quien lo ejerce sufra como consecuencia de ello sanciones o decisiones que le perjudiquen y, por el otro, porque las únicas facultades que comporta son las de exigir el acuse de recibo y la comunicación de la decisión adoptada al respecto o bien la remisión a quien sea competente para tomarla, quien habrá de dar esa respuesta.

En ningún caso conlleva el derecho de petición la obligación por parte del poder público frente al que se ejerce de acogerla materialmente.

La Ley Orgánica 4/2001 se ajusta al contenido que históricamente se ha reconocido a este derecho. Así, su art. 1, que lo extiende a toda persona natural o jurídica prescindiendo de su nacionalidad, mientras el art. 29 de la Constitución solamente lo refiere a los espańoles, veda que el peticionario pueda verse perjudicado por el ejercicio de este derecho salvo que comporte delito o falta y, luego, los arts. 3 , segundo párrafo y 8 , segundo párrafo, dejan claro que no pueden canalizarse a través del derecho de petición aquellas solicitudes o pretensiones para las que exista un procedimiento específico. Y es que, como dice la exposición de motivos de ese texto legal del derecho fundamental que regula: «su carácter supletorio respecto a los procedimientos formales específicos de carácter parlamentario, judicial o administrativo obliga a delimitar su ámbito a lo estrictamente discrecional o graciable, a todo aquello que no deba ser objeto de un procedimiento especialmente regulado».

Por otro lado, el art. 11, precisa cómo han de tramitarse y resolverse las peticiones admitidas. De sus prescripciones interesa destacar que el órgano receptor de las mismas, de ser competente, habrá de contestarlas en tres meses desde su presentación y que está obligado, en los supuestos en que no las estime fundadas a recoger, al menos, los términos en los que la petición ha sido tomada en consideración por parte de la autoridad u órgano competente y a incorporar las razones y motivos por los que se acuerda no acceder a ella (apartado 3).

A partir de estas premisas, el Tribunal Supremo decreta la desestimación del recurso de casación al entender que ninguna de las garantías que comporta el reconocimiento del derecho de petición ha sido desatendida y que, consecuentemente, su ejercicio ha sido respetado en todos sus extremos inicialmente por parte de la Administración interpelada y después por el órgano jurisdiccional ante el que se impugnó su actuación, hallándose todo ello así reflejado en el Fundamento Jurídico Quinto de la sentencia que es objeto de este comentario:

En este caso, la sentencia de la Audiencia Nacional ha explicado a la recurrente cuál es el régimen propio del derecho de petición y que la contestación ofrecida por la resolución de 26 de enero de 2015 es respetuosa con los preceptos de la Ley Orgánica 4/2001. Asimismo, ha corroborado la distinta situación en que se halla FEREDE respecto de la Iglesia Católica, no para realizar un juicio 
de igualdad sino para confirmar que la respuesta ofrecida por el Ministerio de Hacienda y Administraciones Públicas era coherente con la petición y suficientemente fundada en Derecho. Es decir, que ofrecía las razones por las que no cabe atenderla.

Esa respuesta satisface el derecho fundamental ejercido por FEREDE, de manera que ninguna infracción del art. 29 de la Constitución o de la Ley Orgánica 4/2001 se puede imputar a la sentencia ni a la Administración. Además, conviene señalar que la respuesta dada a la peticionaria más que exponer la falta de competencia del departamento ministerial autor de la resolución recurrida en la instancia, pone de manifiesto que el ordenamiento jurídico, mientras da cobertura al trato dispensado a la Iglesia Católica, no la ofrece a las Entidades Religiosas Evangélicas de España. Por tanto, carece de fundamento la argumentación que respecto a la competencia articula el escrito de interposición.

En fin, el art. 12 de la Ley Orgánica 4/2001 fija, en coherencia con la naturaleza del derecho de petición, el alcance de su protección jurisdiccional. Así, mediante ella se podrá combatir: a) la declaración de inadmisibilidad de la petición; b) la omisión de la obligación de contestarla en el plazo establecido; y c) la ausencia en la contestación de los requisitos mínimos establecidos en el art. 11 .

Por tanto, admitida a trámite la petición de FEREDE y contestada conforme a este precepto, exponiendo los motivos por los que no se accede a la misma, ningún reproche se puede dirigir contra la resolución impugnada ni contra la sentencia que ha confirmado su legalidad.

Finalmente, hemos de decir que ni la sentencia, ni la actuación administrativa incurren en infracción de los arts. 14 y 16 de la Constitución en ninguno de los apartados invocados por la recurrente precisamente porque se mueven en el marco del derecho fundamental que ha ejercido.

El último de los párrafos que acaba de transcribirse pone de manifiesto, claramente, cuál es la razón por la que el Tribunal Supremo no se ha visto en la necesidad de entrar en el fondo del asunto por lo que respecta a las presuntas vulneraciones tanto de la libertad ideológica y religiosa como del principio de igualdad y, al mismo tiempo, aquel pasaje judicial evidencia las limitaciones que ya de inicio ofrecía la opción de articular la pretensión de la FEREDE por la vía del ejercicio del derecho de petición: puesto que la impugnación jurisdiccional de la actuación administrativa apelaba a una posible lesión indirecta de los arts. 14 y 16 de la Constitución, esto es, derivada de la presunta vulneración del derecho de petición, una eventual ausencia de esta última, como la que fue finalmente decretada, zanjaría la discusión respecto de la implicación en el caso de aquellos otros dos preceptos iusfundamentales.

A lo sumo, al intérprete le cabría cuestionar la aplicación que hace aquí el Tribunal Supremo de cualquiera de los aspectos integrantes del régimen del derecho de petición en su proyección sobre el caso concreto enjuiciado - en 
esta línea se sitúan algunas de las apreciaciones que formulo en el epígrafe siguiente-, y ello no tendría nada de particular, pues forma parte de la crítica que legítimamente puede hacerse al contenido de esta o de cualquier otra resolución judicial, pero más allá de ello no parece que en principio pueda reprocharse a nuestro máximo tribunal de instancia que haya desamparado en modo alguno al recurrente en lo que a la garantía de su libertad e igualdad religiosas se refiere, al no verse estas aquí estrictamente concernidas una vez resuelta negativamente la pretensión acerca del supuesto incumplimiento del art. 29 de la ley de leyes.

Pese a todo, aunque la sentencia del Tribunal Supremo declara no haber lugar a entrar en el fondo del asunto respecto de esos otros preceptos iusfundamentales pretendidamente lesionados - lo que está en concordancia con la perspectiva de enjuiciamiento adoptada—, sin embargo, como se ha visto, sí hace algunas referencias incidentales a la igualdad en materia religiosa que sin duda merecen algún comentario adicional.

\section{REFERENCIAS INCIDENTALES EN LA SENTENCIA AL PRINCIPIO DE IGUALDAD RELIGIOSA}

Es evidente que en el trasfondo de este litigio late la idea, sostenida por la entidad recurrente, de que el régimen jurídico de la financiación de las confesiones religiosas en nuestro ordenamiento resulta discriminatorio en este aspecto concreto, en tanto que solo contempla el acceso de la Iglesia católica al beneficioso sistema de la asignación tributaria en detrimento de todas las demás confesiones y, concretamente en este caso, en perjuicio de la FEREDE promotora del pleito. Ello se encuentra explícitamente formulado de este modo ya en el recurso inicial ante la Audiencia Nacional, en los siguientes términos:

[...] la parte recurrente afirma que la petición hecha por la parte actora, se basa en lo dispuesto en el art. 53.2 de la C.E. en concordancia con el art. 12 de la Ley 4/2001 reguladora del derecho de petición, y sostiene, que aun cuando la resolución impugnada argumenta que la resolución de dicha cuestión excede con mucho de las competencias de la Administración tributaria, no contiene ningún argumento de fáctico ni jurídico que justifique la grave limitación a los derechos de quienes practican el culto religioso evangélico o protestante; y declina conocer del fondo del asunto, pues estima que la casilla tributaria reservada a la Iglesia católica tiene como fundamento el Acuerdo entre el Estado Español y la Santa Sede sobre asuntos económicos de fecha 3 de enero de 1979, pero olvida que la FEREDE, también es titular de acuerdo suscrito con el Estado Español por medio de la Ley 24/1992 de 10 de noviembre por 
la que se aprueba el acuerdo de cooperación del Estado con la FEREDE, es decir, que las entidades religiosas adscritas a dicha Federación de Confesión Evangélico Protestante, también han establecido acuerdos con el Estado, los cuales no podrán diferir en lo esencial de otros semejantes sin ser considerados discriminatorios o atentatorios contra la igualdad ante la Ley o vulneradores de otros derechos fundamentales a los que se hace referencia (SAN de 25 de mayo de 2015, FJ 2º. Las cursivas son mías).

A este respecto, en la fundamentación de su fallo la sentencia de instancia se limitó a constatar la existencia de un tratamiento normativo diferente en esta materia - como no podría haber sido de otro modo, pues este es un dato objetivo incuestionable-, expresado en un contenido muy distinto de los acuerdos suscritos con la Iglesia católica, de un lado, y con las confesiones evangélicas, de otro, y más concretamente en la ausencia en el acuerdo firmado con la FEREDE en 1992 de un precepto similar al del art. II del Acuerdo sobre asuntos económicos con la Santa Sede 9 , pero esa constatación es únicamente explicitada por la Audiencia en el contexto específico del escrutinio sobre la adecuada aplicación de las normas que rigen el derecho de petición, esto es, a los únicos efectos de valorar si la respuesta denegatoria que dio inicialmente la Administración a la pretensión de la entidad peticionaria estuvo o no adecuadamente motivada y fundada en derecho, ya que en dicha respuesta el Ministerio de Hacienda y Administraciones Públicas afirmó carecer de competencia para atender a la solicitud presentada porque ello requeriría, adujo, de la aprobación de un precepto acordado con las confesiones evangélicas semejante al contenido en el actual régimen concordatario con la Iglesia católica.

La resolución de la Audiencia Nacional, como también haría después la sentencia del Tribunal Supremo, dio por buenas las explicaciones de la Administración sobre este punto, y así, no habiendo encontrado el órgano juzgador que se hubiere producido lesión alguna del derecho de petición, ya no hubo lugar a la valoración acerca de una posible vulneración indirecta de los arts. 14 y 16 de la Constitución, de modo que la sentencia recurrida no extrajo ninguna otra consecuencia de la detección de aquella diferencia de tratamiento normativo efectivamente existente en nuestro derecho.

Por su parte, lo que acontece en relación con este aspecto concreto en la sentencia del Tribunal Supremo no difiere en esencia de lo que se acaba de relatar, aunque introduce algún matiz que conviene ahora resaltar en la medida en la que da pie a formular algunas consideraciones adicionales sobre el razonamiento judicial.

9 Cfr. el Fundamento Jurídico Quinto de la SAN de 25 de mayo de 2015. 
En el Fundamento Jurídico Quinto de la sentencia de 14 de diciembre de 2016, como se vio, nuestro máximo órgano jurisdiccional reitera, con intención aclaratoria, que la explícita constatación, en la sentencia de instancia, de la distinta posición jurídica en que se encuentran las confesiones evangélicas respecto de la Iglesia católica en esta materia no tiene relación alguna con la realización de un juicio de igualdad, esto es con la valoración de una posible infracción del art. 14 de la Constitución, sino que se verifica allí en el marco específico de la evaluación del cumplimiento o no de las normas reguladoras del derecho de petición ${ }^{10}$. Sentado esto y declarada la no vulneración de este último derecho fundamental, como pudo comprobarse, en ese mismo Fundamento Jurídico el Tribunal Supremo introduce en su razonamiento un añadido en el que merece la pena detenerse ahora algo más: «[...] conviene señalar que la respuesta dada a la peticionaria más que exponer la falta de competencia del departamento ministerial autor de la resolución recurrida en la instancia, pone de manifiesto que el ordenamiento jurídico, mientras da cobertura al trato dispensado a la Iglesia Católica, no la ofrece a las Entidades Religiosas Evangélicas de España. Por tanto, carece de fundamento la argumentación que respecto a la competencia articula el escrito de interposición».

El Tribunal aparentemente trata aquí de diferenciar y presentar como no implicadas dos cuestiones que, sin embargo, a mi parecer sí lo están, o al menos lo estaban en la argumentación de la inicial resolución denegatoria del Ministerio de Hacienda y Administraciones Públicas, esto es, la falta de competencia del órgano al que se dirigió la petición, de un lado, y la constatación del tratamiento normativo efectivamente diferenciado para unas y otras confesiones, de otro. Porque lo cierto es que esta última constatación tiene lugar precisamente para justificar la referida falta de competencia, en el sentido de que las normas que regulan - diferenciadamente- esta cuestión son normas acordadas entre el Estado y las confesiones y, consecuentemente, según esto, la Administración no podría dar satisfacción unilateralmente a la FEREDE en su pretensión sino que habría de hacerlo por la vía de la negociación con esta entidad religiosa de un nuevo régimen pactado, y es entonces cuando el órgano ante el que se dirige la solicitud se declara incompetente a estos efectos.

En la primera impugnación judicial de la resolución administrativa denegatoria la entidad recurrente alegaba, como se vio, que la declaración de incompetencia del Ministerio de Hacienda y Administraciones Públicas no se

10 «La sentencia de la Audiencia Nacional [...] ha corroborado la distinta situación en que se halla FEREDE respecto de la Iglesia Católica, no para realizar un juicio de igualdad sino para confirmar que la respuesta ofrecida por el Ministerio de Hacienda y Administraciones Públicas era coherente con la petición y suficientemente fundada en Derecho. Es decir, que ofrecía las razones por las que no cabe atenderla». 
había justificado ni este había redirigido la petición al órgano que sí se estimase competente en este terreno ${ }^{11}$; lo segundo fue efectivamente de este modo, pero no así lo primero, puesto que la justificación ofrecida para avalar la incompetencia de aquel departamento ministerial fue precisamente la de que el tratamiento normativo diferente de estas confesiones provenía de un tipo de normas - de origen acordado- cuya modificación no podía producirse de manera unilateral por parte del Gobierno.

Así pues, frente a lo que da a entender el Tribunal Supremo, el Ministerio de Hacienda y Administraciones Públicas claramente expuso su falta de competencia, si bien el hecho de que se apoyase para ello en el carácter acordado de las disposiciones reguladoras de esta materia resulta cuando menos problemático y suscita algunos interrogantes que, quizá, sean los que esté tratando de evitar el Tribunal al deslindar ambos aspectos en la fundamentación de su fallo.

Sin salirnos de momento del ámbito de amparo del derecho de petición y teniendo muy presente la justificación que proporciona el órgano administrativo para declarar su incompetencia ante la solicitud de la FEREDE, en principio se podría discutir no tanto el sentido de dicha declaración como la falta entonces de la consiguiente reconducción de la petición inicial hacia el órgano que sí se estimase competente para atenderla — tal y como alegaba la entidad recurrente-, cosa que no tuvo lugar. A este respecto, hemos de partir de la premisa en cuya virtud los poderes públicos tienen la obligación constitucional de mantener relaciones de cooperación con las confesiones ex art. 16.3, pero no la de celebrar acuerdos con ellas ya que esto último depende en rigor de una decisión puramente discrecional del Gobierno, de manera que en apariencia cabría inicialmente estimar que la instauración por la vía pactada de un estatuto semejante en esta materia a aquel del que ya goza la Iglesia católica, para la FEREDE o para cualquier otra entidad religiosa que pudiera desearlo, constituye una de esas actuaciones discrecionales que en efecto pueden ser objeto del derecho de petición. Si se admitiese este criterio, parecería entonces plausible entender que la explícita declaración de incompetencia debería haber estado acompañada del reenvío inmediato de la petición al órgano administrativo que se considerase efectivamente competente para dar cauce de satisfacción a la solicitud, en este caso concretamente al Ministerio de Justicia

11 Así se caracteriza la posición de la FEREDE ante la inicial resolución denegatoria: «[...] en realidad, añade, la Administración se ha limitado a decir que lo pedido escapa a su competencia pero no lo ha justificado ni dirigido la petición a los organismos competentes y la sentencia, al dar por bueno el proceder de la Administración, incurre en las infracciones del ordenamiento jurídico señala» (STS de 14 de diciembre de 2016, Fundamento Jurídico Segundo). 
en el que se encuentran radicadas las estructuras encargadas de las relaciones entre el Estado y las confesiones religiosas, en el bien entendido de que, de haberse obrado de este modo, tampoco el Ministerio de Justicia se habría visto obligado a satisfacer el objeto de la petición, ya que esta es una nota caracterizadora del régimen contenido en la Ley Orgánica 4/2001, circunscrito, como se sabe, a lo estrictamente discrecional o graciable.

$\mathrm{Y}$, sin embargo, todo este planteamiento tiene, a mi juicio, una falla fundamental.

Como el propio Tribunal Supremo se encarga de recordar en su sentencia desestimatoria del recurso de casación, la ley reguladora del derecho de petición establece claramente, como uno de los presupuestos necesarios para su ejercicio, que no exista ya un procedimiento específico para canalizar las solicitudes o pretensiones de que se trate, pues de ser así estas últimas directamente no podrán ser objeto del derecho de petición al que nuestro ordenamiento confiere un carácter supletorio respecto de los procedimientos formales específicos de carácter parlamentario, judicial o administrativo.

Así las cosas, conviene advertir que ya existe en nuestro derecho un cauce administrativo específico previsto, en apariencia, para canalizar aspiraciones tales como la que dio origen a este pleito casacional, en la medida en la que en la disposición adicional segunda de la Ley 24/1992, por la que se aprueba el acuerdo de cooperación con la FEREDE, se contempla que dicho acuerdo "podrá ser objeto de revisión, total o parcial, por iniciativa de cualquiera de ellas, sin perjuicio de su ulterior tramitación parlamentaria», $y$, por su parte, en la disposición adicional tercera se contempla la constitución de una "Comisión Mixta Paritaria con representación de la Administración del Estado y de la Federación de Entidades Religiosas Evangélicas de España para la aplicación y seguimiento del presente Acuerdo», que en efecto parece ser la sede adecuada para proponer una revisión del régimen acordado que permita el acceso de esta entidad religiosa al sistema de la asignación tributaria.

A ello se refería precisamente la sentencia de instancia, en los siguientes términos:

La conclusión a la que se llega, es que establecer un mecanismo recaudatorio para los fines religiosos de la FEREDE, como el que tiene la Iglesia Católica, debe ser consecuencia de la existencia de un convenio, pacto o acuerdo entre el Estado Español y el Organismo representativo de la correspondiente religión que llegue a establecerlo de esa forma, sin que pueda la Administración, o algún Ministerio del Gobierno del momento establecerlo de forma unilateral. En todo caso, en la Ley 24/1999, como manifestación de dichos pactos, se establecen los mecanismos de modificación o ampliación de su contenido, a los que puedan llegar el Estado Español y la FEREDE, mecanismos que deberán ser observados para lograr la finalidad pretendida por la recurrente, y que en 
todo caso, como queda dicho, y al constituir el derecho de petición un remedio residual cuando pueda adquirirse por otro medio lo que se pretenda, es claro que no se han agotado los trámites ordinarios para llegar a ese reconocimiento pretendido (SAN de 25 de mayo de 2015, FJ 6º).

A la vista de este pronunciamiento, lo que llama la atención es que la Audiencia Nacional declare conforme a derecho una concreta actuación administrativa que apelaba expresamente, como fundamento de su denegación, a la falta de competencia del órgano receptor de la petición, pues se antoja que el razonamiento judicial a lo que debería haber conducido en buena lógica es a determinar que el derecho de petición no fue inicialmente vulnerado, ya que en puridad no fue adecuadamente ejercido, al no encontrarse la pretensión de la FEREDE entre aquellas que podrían constituir su objeto.

A partir de ahí, cualquier otra consideración acerca de la incompetencia o no del órgano receptor de la petición parece estar de más, pues propiamente solo ha lugar a esa valoración de la competencia si se cumplen los presupuestos objetivos del ejercicio del derecho que reclama su ley reguladora, y según lo que expone la sentencia de instancia en el pasaje que acaba de transcribirse este no fue el caso.

Como antes sugerí, acaso sea esta la razón por la que el Tribunal Supremo haya tratado de deslindar ambos aspectos y haya dado a entender, contra lo que explícitamente dice la sentencia recurrida, que en la actuación administrativa impugnada, más que exponer la falta de competencia, se está haciendo otra cosa distinta, esto es, se está constatando simplemente que la diferencia de tratamiento jurídico en esta materia está amparada por el ordenamiento. Obviamente se trata solo de una especulación por mi parte que entraña un juicio de intenciones, acaso equivocado, para el que no tengo sino una mera intuición basada en los razonamientos que acabo de exponer; no obstante, lo cierto es que el Tribunal Supremo parece caer aquí en la misma contradicción, o en lo que yo al menos considero que es tal, en la que por su parte había incurrido previamente la Audiencia Nacional: o existe un procedimiento específico para encauzar la pretensión del solicitante y por tanto no está aquí en juego el derecho de petición - lo que zanja en cierto modo la discusión-, o se convalida judicialmente la inicial declaración administrativa de incompetencia y se admite con ello implícitamente que aquel derecho fundamental sí estuvo aquí en liza - lo que en rigor debería haber conducido al traslado de la solicitud al órgano competenteafirmarse ambas cosas a la vez sin que ello represente un planteamiento básicamente aporético.

Con todo, a mi modo de ver hay otra llamativa paradoja que se intuye tras todo este asunto y que, en esta ocasión, resulta más bien imputable a la 
propia conducta de la FEREDE: si esta entidad consideraba que el diferente tratamiento jurídico dispensado a unas y otras confesiones en este tema carece de justificación y resulta ilegítimamente discriminatorio, entonces es sencillamente obvio que la pretensión de revertir esa situación ya no es algo que se desenvuelva en el terreno de lo estrictamente discrecional o graciable, que es el propio del derecho de petición, sino que estaríamos ante una aspiración ligada a una presunta vulneración del principio de igualdad en el ejercicio del derecho fundamental a la libertad religiosa, para la que nuestro ordenamiento jurídico contempla cauces específicos de impugnación que nada tienen que ver con el derecho de petición.

Si bien se mira, canalizar la pretensión que nos ocupa por la vía de este último derecho, tal y como aquí sucedió, implícitamente supone admitir de algún modo que estamos ante una concesión graciosa que pueden o no realizar los poderes públicos por razones de mera oportunidad, lo que se antoja en cierto sentido incompatible con la afirmación simultánea de que en esta materia se está vulnerando el principio de igualdad y no discriminación.

Es más, si la premisa de la que se parte es la de que el diferente tratamiento acordado vulnera el principio constitucional de igualdad en relación con el ejercicio de la libertad religiosa, tampoco la vía de la revisión del acuerdo con la FEREDE parece ser en rigor la más adecuada, sino que más bien lo sería la del cuestionamiento de la validez de la norma —en sí misma o en su aplicación en un supuesto concreto de la que pudiese entenderse derivada una lesión de un derecho fundamental - en la que se percibe esa tacha de inconstitucionalidad, mediante alguno de los cauces que a tal efecto establece nuestro ordenamiento jurídico.

Dejando ahora de lado el hecho de que, en mi criterio, el mecanismo idóneo para encauzar la propuesta de la renegociación del régimen pactado con la FEREDE tampoco es el del derecho de petición sino, más bien, el que se contempla en el propio acuerdo en los términos que se han relatado, lo cierto es que dicha propuesta podría acaso contemplarse como una solución puramente pragmática ante la constatación de que, en muy escasas ocasiones, nuestros tribunales de justicia o el mismo Tribunal Constitucional han decretado la vulneración del principio de igualdad religiosa pese a que el contenido del régimen acordado con las llamadas confesiones minoritarias difiere sustancialmente, y en no pocos aspectos, del que integra el régimen concordatario aplicable a la Iglesia católica en nuestro país.

Desde esta óptica, la propuesta de modificación del acuerdo de cooperación no dejaría de representar una estrategia dictada por razones políticas o de oportunidad y no tanto orientada por el ánimo de poner en marcha los mecanismos depurativos que requeriría una actuación estrictamente fundada en derecho, pero ello tampoco tendría nada de extraño si se pone en el contexto 
de nuestro vigente sistema de relaciones Iglesia-Estado, en sí mismo fuertemente condicionado en sus orígenes y posterior desarrollo por ese tipo de factores más políticos que jurídicos a causa, primordialmente, del deseo inicial del constituyente de mantener indemne en el nuevo modelo constitucional buena parte del contenido del precedente régimen concordatario con la Santa Sede y de garantizar su encaje en el nuevo régimen iusfundamental, a modo de contrapartida por el apoyo prestado por la jerarquía eclesiástica al proceso de transición a la democracia y en el marco del tan traído y llevado consenso constitucional que necesitó, también en esta materia - especialmente en esta materia, cabría decir-, de la realización de importantes cesiones en aras del buen final de dicho proceso de cambio político en su globalidad; al fin y al cabo, ese tipo de condicionantes extrajurídicos son los que también explicarían el hecho, ciertamente paradójico, de que sea la misma entidad que en su día negoció y aceptó suscribir esta norma acordada la que ahora postule que se trata de una norma inconstitucional por discriminatoria, aunque todo ello es el reflejo de una dinámica que requeriría de una explicación mucho más prolija que la que procede ahora exponer al hilo de estas reflexiones incidentales. Aún así y sin dejar de tener en cuenta este fenómeno tan característico de nuestro derecho eclesiástico del Estado, conviene insistir en que una actitud coherente con aquel postulado según el cual en este caso la norma acordada resulta ilegítimamente discriminatoria, lo que en puridad habría demandado es una actuación impugnatoria como la antes señalada.

Todas estas últimas apreciaciones, en cualquier caso, invitan a realizar una breve reflexión final especialmente a la luz de lo acontecido, en fechas relativamente recientes, a propósito de la invalidación por parte del Tribunal Constitucional de una norma que, aun no formando parte estrictamente del actual régimen concordatario puesto que se integraba en una disposición unilateral del Estado, comportaba un estatuto diferente y más beneficioso para la Iglesia católica en el ejercicio del derecho fundamental de creación de centros docentes universitarios. A ello me referiré seguidamente.

\section{UNA BREVE REFLEXIÓN FINAL}

Como es notorio, entre un amplio sector de la doctrina científica se encuentra muy extendida la concepción de que el diferente tratamiento jurídico que se verifica en los acuerdos con la Santa Sede, de un lado y en los suscritos con las confesiones minoritarias, de otro, así como en otras disposiciones normativas dictadas en su desarrollo, respecto de muchas de las tradicionalmente llamadas materias mixtas o materias de interés común para ambas partes firmantes no constituye vulneración alguna del principio de igualdad religiosa 
sino que es, meramente, un reflejo del tratamiento especifico al que supuestamente serían acreedoras las confesiones religiosas en nuestro derecho, en función de sus características propias o incluso de su mayor o menor arraigo social.

A partir de ahí, solo en el supuesto de que se aceptase esta idea podría tal vez considerarse que la solicitud que realizó en su día la FEREDE no concernía a una pretensión con «fundamento en la alegación de un derecho subjetivo o de un interés legítimo especialmente protegido", si bien seguiría sin cumplirse el ya mencionado requisito legal alusivo a la inexistencia de un procedimiento específico en el que se refleja el carácter supletorio o residual del derecho de petición, y, por lo tanto, según esto, aquella solicitud tendría que haberse hecho efectiva más bien por los cauces previstos en el propio acuerdo; en todo caso, de asumirse que en efecto no fue conculcado el principio de igualdad en el ejercicio de la libertad religiosa, parece que el resultado en cualquiera de estas dos hipótesis procedimentales - ejercicio del derecho de petición o planteamiento de la reforma de la disposición pactada en el seno de la Comisión Mixta creada por el acuerdo- no habría diferido grandemente por lo que atañe al hecho de que, ante cualquiera de ambas opciones, el Gobierno no habría estado obligado a dar satisfacción al objeto de la solicitud y a alcanzar un nuevo acuerdo en el sentido demandado por la FEREDE ${ }^{12}$.

Frente a este escenario hipotético y especialmente a tenor del contenido prestacional que, en ciertos aspectos, caracteriza al régimen concordatario con la Santa Sede y del que por lo general carecen los acuerdos con las confesiones minoritarias, no son pocos los autores que, por el contrario, estiman que algunas de las normas pactadas, así como otras disposiciones unilaterales del Estado en las que asimismo se consagra un diferente tratamiento jurídico

12 A este aspecto se refería de algún modo la sentencia de instancia, apelando a su vez a la jurisprudencia del Tribunal Supremo sobre el derecho de petición, en los siguientes términos: "[...] la denegación de la solicitud no afecta al derecho de petición, pues, como ha declarado el Tribunal Supremo, "el derecho de petición no se transforma en otra cosa por la circunstancia de que, de ser acogida la pretensión que comporte, el que lo ejerce logre una ventaja o deje de padecer un perjuicio. Es connatural al mismo esa virtualidad y, por eso, precisamente se acude a él cuando el ordenamiento jurídico no ofrece otro cauce para obtener lo que se persigue. Pero que produzca tales efectos e, incluso, que pueda fundamentarse en ellos la legitimación para recurrir en vía jurisdiccional no significa que deje de ser lo que es: un instrumento residual para canalizar aspiraciones que no encuentran ninguna otra vía jurídica para ser planteadas y que no comporta la facultad de obtener de los poderes públicos frente a los que se ejerce su satisfacción material” (Sentencia de 28 de febrero de 2009)» (SAN de 25 de mayo de 2015, FJ 4º). 
perceptiblemente más beneficioso para la Iglesia católica que para otras confesiones, vulneran efectivamente el principio constitucional de igualdad y no discriminación en relación con el ejercicio del derecho fundamental a la libertad religiosa.

Este criterio, no obstante, raramente ha encontrado un eco positivo en nuestros tribunales de justicia o en la doctrina del Tribunal Constitucional, y así, como se anticipó, son ciertamente muy excepcionales los casos en los que se ha decretado la nulidad de una norma en este terreno por resultar contraria al art. 14 de la ley de leyes.

Entre ellos puede destacarse la invalidación de la mención a la Iglesia católica que se contenía en el art. 76.1 de la Ley de Arrendamientos Urbanos y que le confería a esta confesión un estatus especial y privilegiado en el contexto de esa disposición, que tuvo lugar en la STC 340/1993, de 16 de noviembre, entre otras razones por entenderse que dicho trato específico carecía de la necesaria justificación y consecuentemente vulneraba el principio constitucional de no discriminación.

Más recientemente, cabe asimismo llamar la atención sobre la STC $131 / 2013$, de 5 de junio, en la que se produjo la declaración de la nulidad, por discriminatorio, del último inciso del apdo. 2 de la disposición adicional cuarta de la Ley Orgánica de Universidades de 2001 que, paralelamente, concedía un tratamiento especial y privilegiado a la Iglesia católica en relación con el régimen jurídico de las universidades privadas, al eximir excepcionalmente dicho precepto a esta confesión del requisito general del reconocimiento de la universidad por ley estatal o de la correspondiente comunidad autónoma.

Esta sentencia presenta diversos focos de análisis y además resultó particularmente polémica, como lo evidencia la formulación de numerosos votos particulares, y por ello merecería sin duda una más extensa glosa que la que procede aquí realizar ${ }^{13}$, pero, por lo que ahora me interesa subrayar, lo cierto es que sentó un criterio inequívoco acerca de la falta de justificación del diferente tratamiento normativo en este caso, asumiendo que ni lo dispuesto en el art. 16.3 de la Constitución ni ningún otro precepto iusfundamental puede servir de base para justificar un tratamiento privilegiado de esta o de cualquier otra confesión religiosa. Es preciso únicamente advertir que el Tribunal aquí estimó que la referida excepción era imputable únicamente al precepto legal mencionado y no estaba ya presente de manera implícita en el correspondiente precepto concordatario, como sostenía por ejemplo el abogado del

13 Me he ocupado ampliamente de este tema en J. R. Polo Sabau (2016), «Las objeciones a la declaración de inconstitucionalidad del régimen especial de reconocimiento de las universidades católicas: análisis de los votos particulares a la STC 131/2013, de 5 de junio», Revista de Derecho Político, 95, pág. 39. 
Estado, pero en cualquier caso el criterio fijado en relación con el principio de igualdad fue claro y resultaría por tanto en principio aplicable en los mismos términos a cualquier otra norma, en este caso de las que integran el régimen concordatario aplicable a la Iglesia católica, pues es sabido que los tratados internacionales - siendo esta la naturaleza jurídica de los acuerdos con la Santa Sede- están también sujetos al control de constitucionalidad como cualquier otra norma con rango de ley.

Si bien es cierto que esta sentencia se muestra, por así decirlo, en extremo cautelosa en el modo en el que se exponen los fundamentos de su fallo, y si bien es igualmente exacta la afirmación de que en esta resolución, desde una cierta perspectiva al menos, no se terminan de llevar los fundamentos expuestos hasta lo que parece habrían de ser sus últimas consecuencias - acaso todo ello propiciado por ese cariz polémico y singularmente espinoso del tema de fondo aquí ventilado - , no lo es menos que la idea que se ve respaldada en la sentencia, en cuya virtud nada hay en nuestro derecho que justifique un trato privilegiado a la religión tradicional y sociológicamente mayoritaria entre nosotros, parece abonar el terreno para futuras impugnaciones de otras normas — también de origen acordado- en las que visiblemente se verifica semejante tratamiento especial y privilegiado.

De ser así, en apariencia tendría más visos de prosperar el cuestionamiento de la constitucionalidad de las normas que permiten el acceso al sistema de la asignación tributaria solo a la Iglesia católica, lo que está en el trasfondo de la pretensión que dio origen a la sentencia del Tribunal Supremo que ha sido objeto principal de este comentario, aunque obviamente este pronóstico ha de ser acogido con la misma cautela dados los antecedentes y la naturaleza particularmente compleja y controvertida del debate jurídico que tradicionalmente ha rodeado a las relaciones Iglesia-Estado en nuestro país. 
